\title{
Right Portion of the Diaphragm
}

National Cancer Institute

\section{Source}

National Cancer Institute. Right Portion of the Diaphragm. NCI Thesaurus. Code C33488.

The portion of the diaphragm in the right side of the body. 